\title{
A framework for managing and assessing ethics in Namibia: \\ An internal audit perspective
}

\section{Authors: \\ Nolan Angermund ${ }^{1}$ Prof. Kato Plant ${ }^{2}$ \\ Affiliation: \\ ${ }^{1}$ Standard Bank, Namibia \\ ${ }^{2}$ University of Pretoria, South Africa}

Correspondence to:

Prof. Kato Plant, Department of Auditing, University of Pretoria, Private Bag X20, Hatfield 0028,

Pretoria,

South Africa

E-mail:

kato.plant@up.ac.za

DOI:

10.15249/11-1-119

\section{Keywords:}

ethics assessment; ethics audit; ethical culture; ethics programme; internal audit; Namibia

\section{Abstract}

The Namibian Governance Code was implemented in 2014 and calls for organisations to manage ethics effectively. Although this Code, as well as legislature, requires ethical behaviour in the workplace, limited research in the Namibian context exists. Firstly, this study proposes an ethics framework that can be used by management to build an ethical culture and also assist internal auditors to assess the effectiveness of an organisation's ethical culture. Secondly, data was collected from managers and senior internal auditors in the financial services industry in Namibia to determine their views of the proposed ethics framework. Management agreed that there is a lack of guidance on ethics management and that such a framework could contribute to building an ethical organisational culture. Internal auditors agreed that the framework could assist the Internal Audit Function (IAF) in assessing ethics. However, it appears that the formal assessment of ethics in Namibia is limited to an assessment of the codes of conduct only. Furthermore, there appears to be a lack of reporting on ethics performance to stakeholders, primarily because participants' organisations have not implemented integrated reporting practices.

\section{Introduction}

In recent years, instances of fraud, corruption, poor governance and the need for improved direction, control, anti-fraud and anti-corruption strategies have moved organisational ethics to the top of many boards of directors' agendas (EthicsSA, 2014; Rossouw \& Van Vuuren, 2010). Organisations are increasingly faced with ethics-related risks that could result in significant reputational damage and financial loss (Talbot, Perrin \& Meakin, 2014:109). The application of right and wrong principles 
in business circumstances (Rogojanu \& Badea, 2011:25) is therefore important for sustainable business success as an ethical organisational culture contributes to effective governance and the achievement of organisational objectives (Masunda, 2013:217).

Prior studies on the concept and practice of organisational ethics focus on, amongst others, the systems, structures or programmes that could be implemented by organisations to build an ethical organisational culture (Dando \& Bradshaw, 2013; Kaptein, 2009; Llopis \& Gasco, 2007). Kaptein (2009:262) describes ethical culture as the informal and formal control mechanisms that prevent unethical behaviour and promote ethical behaviour. He also highlights that ethics programmes are the formal mechanisms used to build an organisation's ethical culture (Kaptein, 2009:261). Llopis and Gasco (2007:98) find that an ethical culture within organisations, specifically ethics programmes, is critical to fighting unethical behaviour. In fact, ethics programmes provide the formal procedures for making ethical business decisions (Dion, 2008:316). Dando and Bradshaw (2013:26) support this view as they find that reminding staff to consider ethical behaviour in their daily decision making minimises ethics risks and builds the organisation's ethical culture.

The link between organisational ethics, ethical culture and ethics programmes does exist. However, it is unclear how an organisation's existing ethical culture impacts an ethics programme's effectiveness (Park \& Blenkinsopp, 2013:531). The internal audit function (IAF) within an organisation can assist in determining how effective the ethics programme is. There are, however, no standard criteria and nor is there a standard approach for auditing ethics (Tabuena, 2009:49). This should not deter internal auditors from auditing ethics, especially as more and more countries are forcing organisations to adopt ethical standards or codes of ethics as part of their governance structures (Carlo, 2007:37). Management needs to design and implement ethics programmes but there is no one-size-fits-all programme as the design is dependent on the type of organisation and its industry (Argandona, 2004:48).

In Namibia, a report issued by the Namibian and United Nations Convention Against Poverty in 2013 highlighted that the Namibian Development Plan (NDP) of 2012 emphasised the need for a national code of ethical conduct regarding private and public entities (Namibia and United Nations Convention Against Poverty, 2013:23). In 2000, the current Namibian president, Dr Hage Geingob, expressed the need for legally promoting ethical values in the public and private sectors (Namibia Institute for Democracy \& Konrad-Adenauer-Stiftung, 2000:8). Nikodemus (2013:9) found that the lack of honesty and dependability at the Namibian Home Affairs departments negatively impacted the department's reputation and performance. A commissioner of ethics in the public sector, as well as mandatory ethical codes of conduct for Namibian public servants, could solve these problems (Tjirera, Haimbodi \& Hopwood, 2012:2; Links \& Haimbodi, 2011:2). With this need for ethical guidance in the public and private sectors there has been a drive to promulgate legislation and governance codes in Namibia. Furthermore, Asemota (2003:14) found that the lack of an ethical tone among top management contributed to the decline in Namibian workplace ethics, but that having clear ethics policies and monitoring the effectiveness of ethics programmes could counteract this (Asemota, 2003:2). 
Recently, in 2014, the Namibian Governance Code (hereafter referred to as the NamCode) called for organisations to manage ethics and build an ethical culture by implementing ethics programmes in Namibian organisations. Furthermore, in line with best-practice governance frameworks, such as the 3rd King Report on Governance (hereafter referred to as King III) issued by the Institute of Directors for Southern Africa (IOD), the ethics performance of the organisation (including its ethics programme) must be audited, assessed or evaluated by both internal and external assurance providers (IOD, 2009b:21). The Ethics Institute of South Africa (EthicsSA) highlights that a key role-player in performing such an internal assessment is the IAF (EthicsSA, 2014:2).

The aim of this study is to propose an ethics framework based on the guidance of the NamCode and King III that can be used by management within organisations to build an ethical organisational culture and by internal auditors to assess the effectiveness thereof. Firstly, the research methodology applied in this study to achieve the research objective is described. Secondly, the literature review examines the concepts of ethical culture and ethics management as a means of building an ethical culture. In addition, the role of the IAF in assessing ethical culture within organisations is discussed. Finally, the findings, which include the proposed ethics framework, conclusion and recommendations, are presented.

\section{Research methodology}

\subsection{Literature review}

The literature review was used as a basis for developing the ethics framework by examining the concepts of ethical culture and ethics management, including the use of ethics programmes, to build an ethical culture within organisations. Furthermore, the role of the IAF in assessing the ethical culture, including the effectiveness of ethics programmes, is discussed.

\subsection{Empirical study}

The empirical study entailed data collection through semi-structured interviews with ten participants from five organisations in the financial sector in Namibia. These organisations were purposively selected because they adhere to Namibian governance requirements and they all have IAFs. Although only five organisations were included in the study, these organisations are listed on the Namibian stock exchange and represent the banking sector as well as financial and non-financial regulators in Namibia. Participants included chief audit executives (CAEs) or senior members of IAFs and senior management respectively. These participants were interviewed as they could provide insights into the ethics management and ethics assessment practices within their organisations. For each interview, 8 questions (based on the literature review and proposed ethics framework) were used as a point of departure. Questions 1 to 7 focused on gauging participants on their views on ethics management and ethics assessments within their organisations. 
Question 8 was based on the elements of the proposed ethics framework and participants were asked to express their views on the acceptability of these proposed elements and to indicate, where applicable, tools to assess these elements.

\subsection{Limitations of the study}

Although the study makes use of elements of governance codes to build an ethics framework, it cannot be assumed that implementing an ethics framework within organisations alone will make a good corporate citizen. The study is also limited in that it does not examine the relationship between ethical culture and other organisational processes such as performance management and change management. Although the number of participants is not representative of the population of Namibian organisations, for purposes of this qualitative study, these participants provided insights into ethics management and ethics assessment within organisations.

\section{Literature review}

\subsection{Ethical culture of organisations}

Organisations are made up of diverse people from various cultures that intertwine to achieve common strategic and operational goals. Sinclair (1993:63) supports this by stating that the manner in which employees behave collectively to achieve these objectives, can be defined as the organisational culture. However, employees' behaviour alone cannot form the organisational culture, as the shared values and beliefs of employees also form part of the culture (Schwartz, 2013:40).

Ethical culture is a subcomponent of the organisation's culture and consists of three elements, namely, ethical leadership, ethical values and ethics programmes (Schwartz, 2013:41). With reference to ethical leadership, several authors highlight the role that leaders can play to enhance ethical behaviour in organisations (Demirtas, 2015:280; IOD, 2009a:20; Mayer, Aquino, Greenbaum \& Kuenzi, 2012:151; Miao, Newman, Yu \& Xu, 2013:642). Miao et al. (2013:642) find that ethical leadership is defined as leadership that explicitly communicates ethical messages, sets and monitors ethical behavioural standards and makes ethical decisions in an observable manner. In fact, there is an inverse relationship between ethical leadership and unethical behaviour in an organisation (Miao et al., 2013:641). Demirtas (2015:280) supports this in agreeing that ethical leadership and ethical values reflected by leaders directly impact the manner in which subordinates perform their work. King III also emphasises senior management's responsibility to build a sound ethical foundation and to manage ethics effectively (IOD, 2009a:20).

In contrast, it appears that a weak ethical culture and, more specifically, weak ethical leadership and values, can be linked to the demise of organisations, which is evident from examples such as Enron, WorldCom and Arthur Andersen (Treviño, Weaver \& Brown, 2008:233). Schwartz (2013:41) reiterates that a strong ethical culture not only 
deters illegal behaviour and unethical corporate scandals but also improves the ethical behaviour of all staff. Vitell and Encarnación (2006:39) further highlight that employees' perceptions of an organisation's ethical values impact the success of the business and that organisations that are seen as having strong ethical values tend to retain talented staff, attract ethical staff and have committed employees.

Several authors recommend the implementation of formal ethics programmes to build ethical organisational cultures (Argandona, 2004; EthicsSA, 2014; IOD, 2009a, 2009b; Kaptein, 2009; Kaptein, 2015; Llopis et al., 2007). EthicsSA (2014) illustrates that an ethics programme forms part of an organisation's entire ethics management framework (EthicsSA, 2014:5), as presented in Figure 1. According to EthicsSA, (2014:6-10), leadership commitment, together with effective governance structures, supports the development of an ethical organisational culture. Furthermore, the establishment and maintenance of a sound ethics management programme is a necessary component of the ethics management framework. Finally, an independent assessment of the effectiveness of the ethics management framework is needed to evaluate the organisation's ethics performance which should be reported to both internal and external stakeholders. These elements of an ethics management framework are further addressed in Section 3.2.

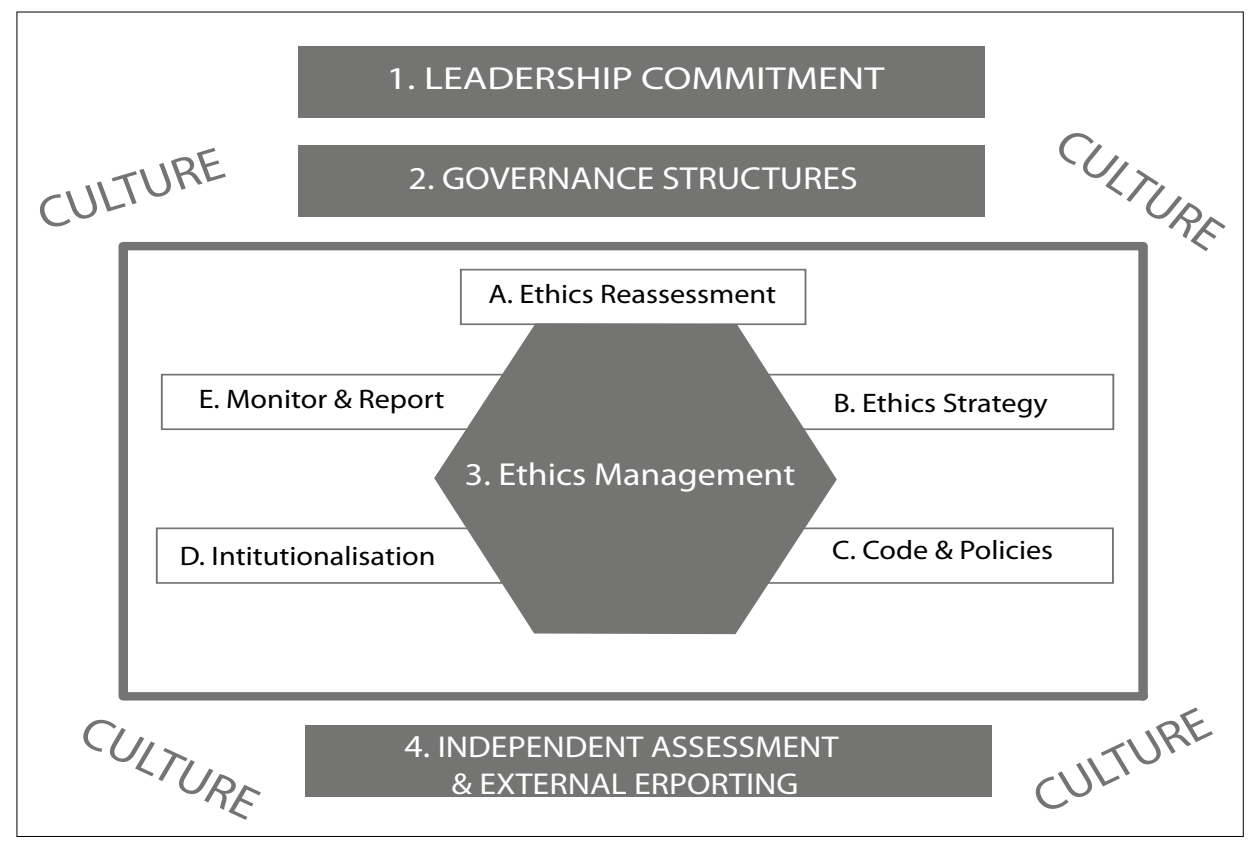

Figure 1: Ethics management framework

Source: EthicsSA, 2014:5 
The purpose of any ethics management framework is to define the standard of ethical behaviour, to inspire consistent ethical behaviour among staff, to encourage ethical leadership from the board and management, and to promote the monitoring, discussion and enforcement of compliance with the standards of ethical behaviour (Kaptein, 2009:263). Understanding the elements of an ethics management framework allows internal auditors to understand what to audit when assessing ethics programmes (refer to Section 3.4 where this is further addressed). An ethics management framework includes all the strategic and operational initiatives required to enhance the ethical culture of an organisation, while ethics programmes refer to the operational aspects (Brown, Mendenhall \& Kramer, 2003:31; EthicsSA, 2014:3; IOD, 2009a:21; Kaptein, 2015; Namibian Stock Exchange [NSX], 2014).

Guidance by the Namcode, King III and EthicsSA can be used by management of Namibian organisations to build effective ethics management frameworks. This guidance is discussed below and used as a point of departure in developing an ethics framework that can provide guidance to IAFs when auditing ethics, thus contributing to strengthening the organisation's ethical culture.

\subsubsection{Leadership commitment}

The ethics tone should be set by the leadership of an organisation (EthicsSA, 2014:5). King III supports this view, requiring that ethics management be integrated into the organisation's strategy by appointing an ethics expert to the board of directors who takes responsibility for managing the ethical culture of the organisation (IOD, 2009b:5-10). This includes the setting of ethics objectives, the allocation of appropriate resources to the ethics programme, and the inclusion of ethics in business communication, policies and business agendas (IOD, 2009b:5-10). The Namcode supports this by highlighting that the board of directors should have the necessary ethics expertise, either by appointing individuals with such capacity to the board or acquiring it through board training and advice (NSX, 2014:24-26). The CEO, or an appropriate executive board member, should also be tasked with being the visible link between the board's ethics expectations and the management of ethics within an organisation (NSX, 2014:24-26).

\subsubsection{Ethics governance structures including the ethics management process}

The EthicsSA recommends the establishment of an ethics office and an ethics committee (EthicsSA, 2014:5). King III expands on this by requiring these ethics management structures to have formal assigned duties, the ethics committee to be a board subcommittee and the ethics officer to manage the operational aspects of the ethics programme (IOD, 2009b:5-10). The ethics office should be run by the ethics officer, can be centralised or decentralised (with ethics champions) and should both monitor ethical behavioural standards and report regularly on the organisation's ethics performance in a formal, written internal ethics report to management (IOD, 2009b:5-10; NSX, 2014; IOD, 2014:24-26). 
As illustrated in Figure 1, the ethics programme consists of an ethics risk assessment, an ethics strategy, a code of ethics and related policies, the institutionalisation of ethics and the monitoring and reporting of ethics performance. Each one of these elements contributes to establishing an effective ethics management process within organisations (EthicsSA, 2014:5). The purpose of this study is not to provide a detailed discussion of each of these elements, but rather to focus on the independent assessment of ethics programmes as an important element of an organisation's entire ethics management framework.

Firstly, conducting regular ethics risk assessments and compiling an ethics risk and opportunity profile should be a priority within organisations (EthicsSA, 2014:5; NSX, 2014:24-26). An ethics risk assessment is an important element of the ethics programme and should be conducted by the ethics office on a regular basis to identify and measure ethics risks such as reputational risks to the organisation, loss of investor confidence and non-engagement with organisational stakeholders (Rossouw \& Van Vuuren, 2010:221). The ethics risk profile which results from the ethics risk assessment allows the board to set the ethical values and standards by identifying the internal and external stakeholders who define ethical and unethical behaviour and also allows the organisation to form a perception of its ethics performance (IOD, 2009b:2). Rossouw and Van Vuuren (2010:225) highlight that an ethics risk assessment is a necessary step prior to developing a code of ethics to address the ethics risks (Rossouw \& Van Vuuren, 2010:234).

Secondly, an ethics strategy for managing ethics and an ethics plan that ensures that staff understand and comply with the ethical standards should be developed and implemented (EthicsSA, 2014:5). This strategy and plan could include many activities, such as ethics training, identification of internal and external stakeholders, and the development of a code of conduct and related policies based on an ethics risk assessment (NSX, 2014:24-26). A code of ethics should be part of an ethics programme, should be developed with all employees' involvement, should be understandable with clear examples of expected behaviour and consequences for contraventions, and must include employee signoff (Schwartz, 2013:44). Organisations with codes of ethics are seen as organisations with strong ethical values (Valentine \& Barnett, 2002:191). Policies that mitigate the identified ethics risk and exploit ethics opportunities are also necessary (EthicsSA, 2014:5; NSX, 2014:24-26) and should be institutionalised when managing ethics effectively.

The third element of the ethics programme is the institutionalisation of the various ethics interventions identified in the ethics strategy and developed in the form of codes and related policies (EthicsSA, 2014:5). The effective institutionalisation of all the ethics interventions is important to ensure that ethics become real within the organisation (EthicsSA, 2014:13; Rossouw \& Van Vuuren, 2010). The ethics office takes responsibility for the institutionalisation of, amongst others, the organisational code of ethics, the rules of conduct and other related policies, such as a gifts and entertainment policy and a conflict of interest policy (EthicsSA, 2014:13). According to Brown et al. (2003:31), ensuring that ethics compliance forms part of the performance goals of staff also institutionalises the ethics programme. A further intervention could include an ethics communication strategy that formalises two-way communication on ethics between the organisation 
and its internal and external stakeholders, with ethics conflict resolution mechanisms that make provision for resolving ethical dilemmas (NSX, 2014:24-26).

Finally, the EthicsSA recommends that the ethics office reports on the progress of the ethics plan to the ethics committee (EthicsSA, 2014:5). King III and the Namcode further recommend reporting by the ethics office to management and the board via a formal ethics report, including aspects such as the ethics risk identification and assessment, instances of ethical misconduct as well as good ethical behaviour, and details on all ethics-related policies and procedures (IOD, 2009b:5-10; NSX, 2014:24-26). Establishing a function that assesses compliance with ethical standards is also recommended by the Namcode (NSX, 2014:24-26). Schwartz (2013:44) supports this, recommending that an ethics compliance officer be appointed, who reports directly to the board and who administers an anonymous ethics reporting process. A whistle-blowing hotline is essential for monitoring and should be an anonymous monitoring mechanism for internal and external stakeholders to report legal or ethical misconduct (IOD, 2009b:5-10; NSX, 2014:24-26).

\subsubsection{Independent assessment and reporting to stakeholders}

Regular reporting on the company's ethics performance to management and the board and in the annual integrated report to various internal and external stakeholders should also exist (IOD, 2009b:5-10; NSX, 2014:24-26). In recent years, organisations have not only been reporting on their financial performance, but also the social and environmental impact of the organisations' activities in a sustainability report or integrated report (IOD, 2009a:12). The Global Reporting Initiative (GRI) issued a report in 2013 (GRI, 2013) expanding on its original triple-bottom-line reporting (economic, social, environmental) performance indicators recommended in 2003 (GRI, 2003) to include organisational ethics and integrity that can be used by organisations.

Schwartz (2013:44) emphasises that regular assessment of the ethics programme by IAFs is a key element of the ethics programme and the Namcode subscribes that the IAF be responsible for assessing the ethical culture of the organisation as well as the adequacy and effectiveness of the ethics programme (NSX, 2014; IOD, 2014:24-26). External ethics reporting by the board forms part of the integrated report and an external auditor will verify the detail in the report and issue an assurance statement on the materiality, completeness and reliability of the information on ethics performance (Global Reporting Initiative, 2013:85; IOD, 2009b:5-10; IOD, 2014:24-26).

Although the value of implementing a sound ethics programme is highlighted above, Jennings (2005:24) indicates several pitfalls to consider when implementing these programmes. For example, appointing a single ethics compliance officer responsible for the entire organisation could result in isolation, and management thus shifting the total responsibility for this function onto the shoulders of this officer. Furthermore, if the ethics programme is not driven by the board, or management does not deal with inconsistent behaviour, the ethics programme will not be effective (Jennings, 2005:26). 


\subsection{The role of the IAF with regard to ethics in organisations}

The role of the IAF is defined by the Institute of Internal Auditors (IIA) and includes a mandatory requirement to assess an organisation's ethics programmes and activities (IIA, 2013a:11). An assessment of the ethical culture by the IAF provides audit committees with an objective and independent picture of the ethical culture of the organisation (IOD, 2014a:3). The Chartered Institute of Internal Auditors (2014:3) in the United Kingdom supports this by highlighting that boards of organisations need assurance and confidence that acceptable values and ethical practices exist as part of the organisational culture. The importance of an acceptable ethical culture must be driven by the board mandating IAFs to be involved in ethics matters, such as fraud assessments, health and safety audits, conflict of interest matters and other governance-related matters (Brown, 2003:31).

Hubbard (2002:57) emphasises that ethics forms part of the control environment of an organisation and that a weak ethical culture contributes to weaknesses in other business controls. This is supported by Boyle, Hermanson and Wilkins (2011:4) who state that when auditors assess the ethical culture they are actually auditing the control environment of the organisation. Brown, Mendenhall and Kramer (2003:30) find that internal auditors need to be involved in assessing compliance to codes of ethics, educating staff on the code, and facilitating ethics self-assessments and ethics risk assessments to identify key ethics risks. Childers (2005:34) supports this, positing that strengthening ethics programmes in business involves identification of ethics risks and developing strategies to address those risks. Internal auditors provide recommendations and strategies for addressing these risks as part of their advisory roles as prescribed by the International Standards for the Practice of Internal Auditing (hereafter referred to as the Standards) (IIA, 2013a).

Therefore, in order to audit ethical culture, the IAF should understand the important elements thereof, namely ethical leadership, governance structures (including legislation) and ethics programmes. In fact, the Chartered Institute of Internal Auditors (2014:13) found that organisations such as Goldman Sachs and Barclays believe in putting more than a hundred thousand employees through ethics awareness training to strengthen their ethical culture. In auditing the ethics management framework (including the ethics programme), the guidance provided by the Namcode, King III and the EthicsSA is used as a point of departure.

\subsubsection{Leadership commitment}

The Namcode (NSX, 2014) highlights that the IAF can assess the adequacy and effectiveness of the ethics programme by enquiring whether the board and management demonstrate ethical leadership and ethics expertise as part of their performance assessments, and evaluating the adequacy of the assessment criteria. The IIA (2011:15) supports the assessment of the ethical leadership by requiring the IAF to measure the ethical attitude of management as part of auditing the organisation's control environment. 


\subsubsection{Ethics governance structures}

The IAF can assess the functioning of the ethics structures such as the ethics office, the ethics committee and the ethics communication strategy of the organisation (IOD, 2009b:8-9). More specifically, whether ethics is discussed at board level and whether the ethics office is effectively resourced must be determined (EthicsSA, 2014:12). It is also important to assess the reporting line of the ethics office and the functioning of the office itself (IIA, 2011:17). With regard to the elements of the ethics management process, the IAF could assess:

- whether all the ethics risks were identified and make recommendations on how to mitigate these risks;

- the application of the ethics strategy and the adequacy of the ethics structures, ethics plans, ethics communication and ethics training (IOD, 2009b:8). Enquiring whether the ethics strategy is in line with the organisation's strategic objectives and risk profile is also important (EthicsSA, 2014:12);

- ethics policies and activities - whether employees exhibit behaviour in line with these codes and policies and whether management effectively communicates these policies (IIA, 2012a:7; NSX, 2014). Dubinsky (2002:44) supports this view by highlighting that such assessments should determine whether the activities and policies are reasonable, simple to adhere to and capable of reducing unwanted behaviour;

- the effectiveness of the institutionalisation of ethics process, such as verifying the accreditation of the whistle-blowing hotline service provider and verifying the efficiency of the conflict of interest management system (EthicsSA, 2014:12). Assessing whether management continually advertises the hotline should also be considered (IIA, 2011:16); and

- the effectiveness of ethics monitoring mechanisms such as the whistle-blowing programme, the adequacy of the investigation results of hotline cases (IIA, 2011:16) and the adequacy of the ethics information management system linked to the ethics performance management and reporting system (EthicsSA, 2014:12).

\subsubsection{Independent assessment and reporting to internal and external stakeholders}

The IAF plays an important role in assessing the effectiveness of the organisation's ethics programme by performing regular ethics audits or assessments (IIA, 2012). The IOD (2009b:8) is explicit in stating that the IAF should report the results of the ethics audit to management and the board as required by the IIA Standards. The IIA published a practice guide in 2012 which provides guidance to internal auditors when evaluating ethics-related programmes and ethical culture (IIA, 2012). This guidance includes, amongst others, the use of employee surveys and ethics maturity models to assess the effectiveness of an organisation's ethics programme. 


\subsubsection{Background: ethics audit process}

When conducting an ethics audit engagement, the internal audit process prescribed by the IIA is applied with specific focus on ethics (Plant, 2008:15-28). The IIA Standards highlight that the audit engagement must be planned (reviewing codes of conduct/ ethics, ethics and compliance departmental structures); risks and controls related to ethics programmes must be assessed; the effectiveness of the associated controls of the ethics programmes must be tested and, finally, the results of the tests must be reported to senior management and the board (IIA, 2012a:10-12). When performing such an ethics assessment, the IAF can use various audit tools and techniques, such as employee surveys and ethics maturity models, to assess the 'state of ethics' within an organisation and to rate the ethics control environment (IIA, 2012:10-12; EthicsSA, 2014:5).

\subsubsection{Ethics audit tool: employee surveys}

Employee surveys can be used as a gap analysis between what management wants and what employees experience (IIA, 2012a:19) with reference to ethics. Allen (1995:53) insists on using a survey, but states that the survey results should be evaluated by an external firm that specialises in assessing survey results. The disadvantage of a survey is that one cannot always send these out to all employees in a large organisation as this can be time-consuming and thus it cannot be guaranteed that the results are representative of the total population (Allen, 1995:54). It is therefore recommended that the survey be followed up with interviews of key staff and executives (including board members) (Allen, 1995:55).

The IIA (2011:15) requires the IAF to measure the ethics attitude of management as part of auditing the organisation's control environment. This can be done through annual anonymous surveys known as climate surveys (IIA, 2011:15). The IIA (2012a:7-10) clearly states that in order to assess the ethical culture and the application of the ethics programme, the IAF can make use of such an ethical climate survey, one of the few accurate means of assessing ethical climate within an organisation (IIA, 2012a:19). Employees complete the survey by responding to statements on the elements of the ethical culture, such as ethics policies, organisational objectives and culture (IIA, 2012a:18-23). It is important to note that the survey can be done at organisational or departmental levels and could be integrated with a specific internal audit engagement at these levels (IIA, 2012a:25).

\subsubsection{Ethics audit tool: maturity models}

Similar to an audit rating methodology to assess ethics, a model that rates the maturity of the ethical culture within an organisation can be applied by the IAF (IIA, 2012a:13). A model provides the framework for the ideal ethical culture or ethics programme criteria, indicates how improvements can be made and provides opportunities to benchmark an organisation against other organisations (IIA, 2013b:2). Maturity models are applied by internal auditors because they can be used to gauge management's expectations and can also be used in conjunction with the organisation's risk tolerance levels to decide on the level of maturity (IIA, 2013b:1). In fact, a maturity model is an effectiveness assessment tool as a more mature activity means there is a better chance of achieving objectives (IIA, 2013b:1). 
In an ethics maturity model, each ethics programme and culture element is rated along a maturity scale ranging from immature to mature based on various attributes. An attribute in this case would be an element of the ethics programme, such as institutionalisation or the ethics structures (IIA, 2012a:13-18). Furthermore, each attribute is rated along a maturity scale based on its level of maturity. These attributes can range from not having ethics policies in place (immature rating), to having formally signed off and discussed ethics policies in place (mature rating) (IIA, 2012a:13). Some of the elements that are rated are: the code of ethics, management commitment to business ethics, the level of ethics awareness and training, and the ethical structures and accountability (IIA, 2012a:13-18). The IIA (2012a:7) highlights that a maturity model provides a basis for the IAF to verify the maturity rating through testing and then report on the strengths and weaknesses of the ethical culture.

Against this background, an ethics framework is proposed that can be used by managers to manage ethics within their organisations and by internal auditors to perform ethics assessments and subsequently contribute to building an improved ethical culture.

\section{Findings}

As detailed in Section 2, the study firstly presents an ethics framework (based on the literature review) and secondly reports on the views of managers and internal auditors from organisations in the Namibian financial sector. The proposed ethics framework is presented first (see Section 4.1 and Table 1), followed by a discussion of participants' views on: (1) ethics management and ethics assessment standards; (2) ethics assessment practices within their organisations; and (3) the elements of the proposed ethics framework.

\subsection{Proposed ethics framework}

Table 1: Proposed ethics framework for managing and assessing ethics

\begin{tabular}{l|l}
\hline Framework (elements) & \multicolumn{1}{c}{ Assessment tool/method } \\
\hline An ethics expert sits on the board of directors. & $\begin{array}{l}\text { - Review the board minutes to assess the } \\
\text { contributions made by the expert in ethics-related } \\
\text { matter discussions. } \\
\text { - Assess whether the person is adequately qualified } \\
\text { through performance of an interview and detailed } \\
\text { reference checks. } \\
\text { - Vet ethical qualifications to determine authenticity } \\
\text { thereof. }\end{array}$ \\
\hline The board has set ethics objectives. & $\begin{array}{l}\text { Obtain the strategic objectives of the organisation } \\
\text { and assess whether ethics and values are } \\
\text { incorporated. } \\
\text { - Verify that the board approved the code of ethics. }\end{array}$ \\
\hline
\end{tabular}


Ethical leadership (continued)

The CEO is responsible to the board for ethics management.
- Assess the quality and content of the reports that the CEO presents to the board quarterly.

- Review the minutes of the board meetings and management committee meetings and determine the quality and content of the ethical matters reported on by the CEO.

- Assess whether the CEO has attended ethics training.

- Assess the CEO's job description for this responsibility.

The board has allocated appropriate resources to the ethics programme. (have programme goals been met?) and whether
- Assess the effectiveness of the ethics programmes any ineffectiveness can be related to a lack of resources.

- Review the budget items related to the ethics programme for adequacy.

- Review the organogram and reporting lines of the ethics office and its staff.

- Obtain a list of ethics incidents and assess how these were resolved.

Ethics forms part of business communication and business agendas.
- Obtain the minutes and agendas of ethics office and social and ethics committee meetings and assess whether and how ethics matters are discussed and communicated.

\section{Ethics governance structures}

Ethics office and ethics officer who manages the operational aspects of the ethics programme exist.
- Assess the job descriptions for specific ethicsrelated tasks.

- Assess whether these tasks are executed and linked to Key Performance Indicators.

- Assess the reporting structure of the ethics office.

- Assess the report and verify the reported content and whether it has been signed off by the board and distributed to the relevant personnel.

- Perform a quality review on the operations of the ethics office in line with their mandate.

- Assess the committee's reports, minutes and agendas for ethics-related matters.

- Assess the committee's composition and review their minutes to assess the quality of the discussions.

\section{Risk assessments}

\begin{tabular}{l|l}
\hline Regular ethics risk assessments are conducted. & $\begin{array}{l}\text { - Evaluate the adequacy of the assessment process } \\
\text { and assess the effectiveness of the methodology } \\
\text { that is used. }\end{array}$ \\
\hline Ethics risk and opportunity profile is prepared. & $\begin{array}{l}\text { - Assess the quality and implementation of the } \\
\text { actions to address the risks and opportunities. }\end{array}$
\end{tabular}




\section{Ethics strategy and plan}

An ethics plan which includes strategies on how to establish an ethical culture is established by the ethics committee.

- Assess whether the plan is communicated to staff and assess compliance with the plan.

- Review the plan, assessing the timelines and implementation.

- Perform a climate survey after the plan is executed to establish whether the ethical culture improved.

\section{Code of ethics and related policies}

Board approved a code of ethics and rules of conduct exist and are signed off by employees on a regular basis.

Policies (in regard to conflict of interest, gifts and entertainment) that mitigate the identified ethics risks and exploit the ethics opportunities are established.
- Verify list of employees against the sign-off sheets and assess the adequacy of the sign-off intervals.

- Assess whether the policies are communicated to all staff.

- Interview staff and determine whether they are aware of the requirements.

- Test compliance with the policies and whether they are regularly reviewed for relevance.

Ethics communication strategy that formalises two-way communication on ethics between the company and its internal and external stakeholders is implemented.

Ethics conflict-resolution mechanisms that make provision for resolving ethical dilemmas.
- Assess the communication policy for ethics elements and whether it provides clear communication channels.
- Assess the compliance with the policies by selecting a few conflict cases.

\section{Institutionalisation}

Regular management-driven ethics awareness campaigns are held during induction as well as on an ongoing basis.

Ethics training run by the ethics office based on the code of ethics and rules of conduct is conducted.

Identification of internal and external stakeholders who define ethical and unethical behaviour is part of the stakeholder relations process.

Ethics compliance forms part of performance goals of staff.

IAF is involved in ethical matters such as fraud assessments, health and safety audits, and conflict of interest matters.
- Assess the campaign content against the ethics strategy and plan and review the attendance registers.

- Assess the qualifications of the facilitators.

- Assess the training material and attendance by staff for adequacy.

- Assess the qualifications of the ethics officer.

- Assess the stakeholder management programme and determine whether all stakeholders have been identified.

- Review the job descriptions and performance assessments and assess whether staff goals contain ethical elements such as values.

- Assess the criteria used for the ratings given in regard to performance goals.

- Assess the internal audit charter to determine if these items are specifically included.

- Perform a quality assurance review on these matters.

\section{Monitoring and reporting}

Ethics office reports on the progress of the ethics plan to the ethics committee.
- Assess the plan against the report content.

- Assess the quality of the reports. 


\section{Monitoring and reporting (continued)}

Ethics office reports to management and the board includes aspects such as:

- ethics risk identification and assessment;

- ethical misconduct as well as good ethical behaviour; and

- details relating to all ethics-related policies and procedures.

Board and management performance assessment have ethical leadership as a part thereof.

Whistle-blowing hotline, as an anonymous mechanism for internal and external stakeholders to report legal or ethical misconduct, exists.
- Assess the content of the reports and the minutes of the meetings to determine whether reported items are discussed.

- Assess the quality of the actions that address the reported matters.

Independent assessment and report to internal \& external stakeholders

- Regular internal assessment of the effectiveness of the ethics programme by the IAF.

- Results of assessment reported to the board and audit committee.
Reporting on the company's ethics performance to stakeholders in the annual integrated report or sustainability report.

External auditor verifies the detail in the report and issues an assurance statement on the materiality, completeness and reliability of the information related to ethics performance.
- Perform a quality assurance review to determine quality of the internal assessment.

- Assess whether ethics audits are part of the audit plan.

- Assess the validity of the reported items in the integrated report.

- Inspect the assurance statement and assess the information against the ethics findings raised in the management letter.

- Perform a quality assurance review to determine external assessment.

\subsection{Views of participants}

\subsubsection{Section 1: Ethics management and ethics assessment standards}

From the empirical study conducted, it is evident that there is a lack of legislative guidance regarding the implementation and assessment of ethics programmes within organisations. Apart from listed organisations which are compelled to apply the King III principles, the only other guidance is from a general governance approach where participants' organisations rely on the appointment of people with sound ethical values and the participation of a board of directors which is committed to good governance practices. The majority of participants' organisations have adopted a governance code, whether it be the Namcode or King III, but the requirements for implementing and auditing ethics programmes were not known, apart from the implementation of ethics hotlines. This was in contrast to the literature, whereby the IIA sets mandatory standards that require IAFs to assess ethics (IIA, 2013a:11). One participant (from management) was however aware of the need for implementing ethics-related policies and assessing compliance to these (granted that this participant was an ethics officer). 
Regardless of whether the participants from both management and internal audit were aware of the requirements to manage and evaluate ethics, they all agreed that having a mature ethical culture in their organisations, as well as assessing the ethical culture would add value to their organisations' stakeholders. They believed stakeholders would see the organisation as being ethical and managing its risks. Furthermore, they felt that internal audit as an independent assessor of ethics, would indicate the robustness of the organisation's ethics programmes to stakeholders. Some participants even believed that stakeholders would see this as a proactive step in reducing fraud and financial losses. These findings align to the literature whereby EthicsSA (2014:6-10) and Treviño, Weaver and Brown (2008:233) all agree that a strong organisational culture and the assessment thereof could have prevented the demise of certain organisations such as Enron.

\subsubsection{Section 2: Views on ethics assessment practices within organisations}

The majority of participants agreed that the IIA Standards are a good start to assessing ethics but could not be used in isolation as more specific tools were needed for assessing the effectiveness of, amongst others, the ethics programme. These findings align with the literature whereby the IIA provided a practice guide in 2012, in addition to the Standards, that provides tools internal auditors can use when evaluating ethics-related programmes. These tools included the use of surveys and ethics maturity models (IIA, 2012). The development of practice guides and practice advisories relating to these ethics assessment tools are also recommended by participants. A participant (from management) warned that internal auditors should not use the generic internal audit approach for an ethics culture assessment. Most participants (from internal audit) believed that providing an audit opinion (assessment rating) on the ethical culture was the biggest challenge experienced with such audits. This view is in contrast to the literature indicating that a climate survey is regarded as one of the few accurate means of assessing ethical climate within an organisation (IIA, 2012a:19). Obtaining audit evidence for ethics audits was also a challenge experienced by some internal audit participants as the criteria against which to assess the evidence is difficult to determine as stated by participants, mainly because of the interpretative nature of ethics. Using the right tool and method to audit ethics programmes might be ways to overcome these challenges as indicated by some of the internal audit participants.

\subsubsection{Section 3: Proposed ethics framework}

\subsubsection{Ethical leadership}

Interestingly, the majority of participants (from management) and half the participants (from internal audit) did not believe that it was important to have an ethics expert at board level as they felt that all board members should set the tone and be sufficiently skilled in ethics matters. They felt that the board needed access to an ethics expert as and when the need arose because industry-specific knowledge at board level was more important for daily board functioning than expert knowledge on ethics. This finding was in contrast to the literature, specifically King III, which states that for ethics management 
to be integrated into the organisation's strategy, an ethics expert must be appointed to the board of directors (IOD, 2009b:5-10).

None of the participants had an ethics expert at board level within their organisations. Participants (from management and internal audit) had differing views on whether the CEO should be responsible for ethics management. Some felt that independent reporting on ethics matters to the board was needed and the CEO would not be independent, while others felt that ethics needed to be operationalised and that is why the CEO needed to be responsible.

\subsubsection{Ethics governance structures}

Participants agreed that it was important to have ethics governance structures in place as they help drive their organisation's ethical culture by assigning responsibility for ethics and showing that ethics matters are reported on and management is willing to take action. However, participants agreed unanimously that the responsibilities be shared by having an audit committee that takes responsibility for the ethics oversight and having ethics champions in each department instead of having one ethics officer for the entire organisation. In terms of the literature, King III and EthicsSA support the decentralisation of the ethics officer function and the establishment of a board subcommittee responsible for ethics (IOD, 2009b:5-10; EthicsSA, 2014:5).

\subsubsection{Ethics risk assessment, strategy and plan}

A lack of understanding was noted when it came to the ethics risk assessment and ethics strategy and ethics planning elements of the framework. Although the participants agreed that it was important to have these elements, the ethics risk assessment is not a separate item at the participants' organisations but formed part of the annual risk assessment. Also, the ethics plan and ethics strategy within participants' organisations is part of general operational plans such as culture-building and team-building initiatives. One can regard the lack of specialised ethics skills within organisations as contributing to this selective application of these ethics programme elements.

\subsubsection{Code of ethics and ethics-related policies}

The implementation and importance of ethics-related policies was noted among most participants. All participants believed that the policies provided needed to be explained to staff and that it be demonstrated to them that the organisation prioritised ethics and would hold staff accountable for any breaches. This is supported by the literature (IOD, 2009b:5-10; NSX, 2014:24-26) which states that ethics policies be communicated and signed off by staff to indicate their understanding. Although the literature highlights that non-compliance with ethics policies should be reported to governance committees, participants indicated that there were no specific ethics conflict-resolution policies or ethics communication strategies in their organisations - these policies and strategies form part of the general conflict resolution and stakeholder communication policies. 


\subsubsection{Institutionalisation of ethics}

Similarly, participants agreed on the importance of institutionalising ethics through ethics training, ethics awareness, ethics goals on the performance assessments and the IAF's involvement in fraud assessments, health and safety audits, and conflict of interest matters. These findings are supported by the literature as King III and the Namcode support the implementation of ethics training, ethics performance assessments and IAF's involvement in health and safety audits (IOD, 2009b:5-10; NSX, 2014:24-26). Participants believed staff need constant reminding of the ethics programme requirements and need to be held accountable through performance assessments. In addition, participants also noted that the independence of the IAF added value to the organisation's ethics initiatives. Although the majority of participants agreed that these elements should be implemented in their organisations, it appeared that institutionalisation initiatives were limited to an implementation of a code of conduct only. Again, this leads one to assume that the lack of specialised ethics skills contributes to organisations just implementing ethics-related policies, with limited institutionalisation initiatives. This appears to be an area where internal auditors can add value by becoming the ethics experts or advocates within the organisation.

\subsubsection{Monitoring and reporting ethics performance}

Participants agreed that monitoring and reporting ethics performance were important but are not implemented in the majority of their organisations. Participants also agreed that it was important to have a whistle-blowing hotline to report ethics matters and for the board and management to be assessed on their ethical leadership, but these monitoring and reporting practices are not applied in half of the participants' organisations. The question arises as to whether these organisations really prioritise the monitoring of unethical behaviour. It is therefore suggested by the author that internal auditors should step in to assist management in prioritising monitoring as they have the necessary skills and business knowledge to express the impact of unethical behaviour not being monitored.

With regard to the independent assessment and reporting to stakeholders, participants' responses indicated that internal audit is always involved in assessing the ethics programmes of organisations. This is supported by King III and the Namcode that require IAFs to assess ethics programmes (IOD, 2009b:5-10; NSX, 2014:24-26). There however appears to be a gap in reporting this performance to stakeholders, primarily because participants' organisations have not implemented integrated reporting as yet. Hence there is no use for an external audit function to verify the detail in the report and issue an assurance statement on the materiality, completeness and reliability of the information related to ethics performance. Participants had differing views on whether it was important for external audit to perform this assessment; some believed that they are not ethics experts and so could rely on the IAF's work, while others believed that it was important for validation and would increase stakeholders' confidence in the integrated report. 
In summary, the findings suggest that formal guidance is needed to prioritise ethics within organisations and at the right level within an organisation. It also suggests that internal auditors require more guidance in terms of which tools or methods to use when assessing ethics.

\section{Conclusion}

This study aimed to propose a framework for managing and assessing ethics in the context of the Namibian financial sector. The literature review examined the notions of ethical culture and ethics management within organisations. Furthermore, the role of the internal audit function in assessing ethics was also discussed. Based on the literature, a framework for managing and assessing ethics was proposed. For the empirical part of this study, views were obtained from management and senior internal auditors of five Namibian organisations in the financial sector. This study reports on participants' views relating to ethics management and ethics assessment standards and practices within their organisations as well as their views on the proposed ethics framework.

It was found that all participants agreed that having a mature ethical culture in their organisations, as well as assessing the effectiveness of the ethical culture, added value to their organisations' stakeholders. Participants also indicated that the responsibilities for ethics governance structures were integrated and not separated from existing structures within their organisations. Similarly, conducting separate ethics risk assessments and establishing a separate ethics strategy and plan were integrated into the overall risk assessment and strategic planning activities. The majority of organisations agreed to implementing and institutionalising at least codes of ethics. However, limited monitoring and reporting of ethics performance to management and other stakeholders existed within organisations. This could be as a result of limited knowledge of all the elements of a formal ethics management framework.

Finally, it was found that, although internal auditors were involved in auditing ethics programmes, their focus was limited to an assessment of the code of ethics and related policies, with not much attention paid to the other elements of an ethics programme or ethics management framework. With the use of the suggested framework internal auditors can now expand their audit scope and make use of the suggested tools to perform better internal audits and add value to where management needs it. The framework can be used to substantiate IAF's scope on ethics with their organisations' management should there be a dispute regarding the need for an ethics audit on the audit plan.

\section{Recommendations}

It is recommended that organisations prioritise the appointment or training of designated individuals to become ethics experts and assist management in building an ethical organisational culture. It is also recommended that internal auditors play a role as ethics advocates in assessing the effectiveness of organisations' ethical culture. Furthermore, 
the monitoring of ethics behaviour should be prioritised and starting an ethics hotline can be a pro-active initiative. The performance of ethics compliance assessments with specific reference to the effectiveness of an organisation's entire ethics management framework, could add value in enhancing the ethical culture of the organisation.

\section{Areas for future research}

A study of the combined assurance approach to assessing ethics within organisations falls outside the scope of this study but is an area for future research. Furthermore, the study did not go as far as researching the effectiveness of the implemented ethics programme elements and whether the adoption of governance codes can be directly linked to effective implementation of ethics programmes. The latter could also be an area for future research.

\section{References}

Allen, M.B. 1995. The ethics audit. Society for Nonprofit Organizations, Madison. http://0-search.proquest. com.innopac.up.ac.za/docview/221335917/fulltextPDF/10984F2D87094FE3PQ/3? accountid= 14717 [Accessed 13 December 2014].

Anon. 2015. 'Namibia fares well in ethics and risk survey'. The Namibian. 19 May. http://www.namibian.com. na/indexx.php?id=26778\&page_type=story_detail [Accessed 22 May 2015].

Argandona, A. 2004. On ethical, social and environmental management systems. Journal of Business Ethics, 51(1):41-52. https://doi.org/10.1023/B:BUSI.0000032350.51151.0d

Asemota, O. 2003. Ethics and values - are they forgotten in our work place, community and society? Unpublished thesis. Windhoek: Polytechnic of Namibia.

Boyle, D.M., Hermanson, D.R. \& Wilkins, A. 2011. Ethics audits: Implications for internal auditors. Internal Auditing, 26(6):3-8.

Brown, D., Mendenhall, S. \& Kramer, J. 2003. Business ethics programs: Is internal audit playing a proactive role? Internal Auditing, 18(4):28-33.

Carlo, P.R. 2007. Rules of behavior. The Internal Auditor, 64(3):33-37.

Chartered Institute of Internal Auditors. 2014. Culture and the role of internal audit looking below the surface. http://www.iia.org.uk/media/598939/0805-iia-culture-report-1-7-14-final.pdf [Accessed 11 August 2014].

Childers, D. 2005. Ethics as a strategy. The Internal Auditor, 62(5):34.

Dando, N. \& Bradshaw, K. 2013. Rebuilding trust: The role for L\&D. Training Journal, 23-27.

Demidenko, E. \& McNutt, P. 2010. Ethical Maturity Framework and Index. 31 March. www.patrickmcnutt. com/wp-content/uploads/Ethical-Maturity-FrameworkJan08.pdf [Accessed 20 March 2015].

Demirtas, O. 2015. Ethical leadership influence at organizations: Evidence from the field. Journal of Business Ethics, 126(2):273-284. https://doi.org/10.1007/s10551-013-1950-5

Dion, M. 2008. Ethical leadership and crime prevention in the organizational setting. Journal of Financial Crime, 15(3):308-319. https://doi.org/10.1108/13590790810882892

Dubinsky, J.E. 2002. A Companion to Business Ethics. London: Wiley.

EthicsSA (Ethics Institute of South Africa). 2014. Ethics reporting handbook. Pretoria: Ethics Institute of South Africa.

GRI (Global Reporting Initiative). 2013. G4 Sustainability reporting guidelines. Amsterdam: Global Reporting Initiative. 
GRI (Global Reporting Initiative). 2003. G3 Sustainability reporting guidelines. Amsterdam: Global Reporting Initiative.

Hubbard, L.D. 2002. The importance of ethics. The Internal Auditor, 59(1):57-59.

IOD (Institute of Directors in Southern Africa). 2009a. King Code of Governance Principles for South Africa. http://www.iodsa.co.za/resource/collection/94445006-4F18-4335-B7FB-7F5A8B23FB3F/King_III_Code_ for_Governance_Principles_.pdf [Accessed 11 April 2015].

IOD (Institute of Directors in Southern Africa). 2009b. Practice Notes King III Chapter 1 Ethics Management. September. http://www.iodsa.co.za/resource/collection/24CB4885-33FA-4D34-BB84-E559E336FF4E/ KingIII_Ch1_Ethics_Management_September2009.pdf [Accessed 11 April 2015].

IIA (Institute of Internal Auditors). 2011. Auditing the control environment. Altamonte Springs: Institute of Internal Auditors.

IIA (Institute of Internal Auditors). 2012. Evaluating ethics-related programs and activities. Altamonte Springs: Institute of Internal Auditors.

IIA (Institute of Internal Auditors). 2013a. International Professional Practices Framework. Altamonte Springs: Institute of Internal Auditors.

IIA (Institute of Internal Auditors). 2013b. Selecting, using, and creating maturity models: A tool for assurance and consulting engagements. Altamonte Springs: Institute of Internal Auditors.

IIA (Institute of Internal Auditors) 2014. Sustaining an ethical culture. https://na.theiia.org/periodicals/ Public\%20Documents/TaT_June_2014.pdf [Accessed 9 September 2014].

Jennings, M.M. 2005. The seven deadly sins of corporate ethics programs. Internal Auditing, 20(1):24-28.

Kaptein, M. 2009. Ethics programs and ethical culture: A next step in unravelling their multi-faceted relationship. Journal of Business Ethics, 89(2):261-281. https://doi.org/10.1007/s10551-008-9998-3

Kaptein, M. 2015. The effectiveness of ethics programs: The role of scope, composition, and sequence. Journal of Business Ethics, 132(2):415-431. https://doi.org/10.1007/s10551-014-2296-3

Links, F. \& Haimbodi, M. 2011. Governance challenges in the SOE sector. http://www.ippr.org.na/sites/default/ files/IPPR_SOE\%20P7_FINALsml.pdf [Accessed 22 May 2015].

Llopis, J.M.R.G. \& Gasco, J.L. 2007. Corporate governance and organisational culture: The role of ethics officers. International Journal of Disclosure and Governance, 4(2):96-105. https://doi.org/10.1057/palgrave. jdg.2050051

Mayer, D.M., Aquino, K., Greenbaum, R.L., \& Kuenzi, M. 2012. Who displays ethical leadership, and why does it matter? An examination of antecedents and consequences of ethical leadership. Academy of Management Journal, 55(1):151-171. https://doi.org/10.5465/amj.2008.0276

Masunda C. 2013. Corporate governance and the financial performance of locally listed companies on the Namibian stock exchange. Unpublished Master's thesis. Harold Pupkewitz Graduate School of Business at the Polytechnic of Namibia. Windhoek: Polytechnic.

Miao, Q., Newman, A., Yu, J. \& Xu, L. 2013. The relationship between ethical leadership and unethical proorganizational behavior: Linear or curvilinear effects? Journal of Business Ethics, 116(3):641-653. https:// doi.org/10.1007/s10551-012-1504-2

Namibia and the United Nation's Convention Against Poverty. 2013. Gap analysis study report: Namibia and the United Nation's convention against poverty. http:/www.google.com.na/url?sa=t\& $r \mathrm{rt}=\mathrm{j} \& \mathrm{q}=\& \mathrm{esrc}=\mathrm{s} \&$ source $=$ web $\& \mathrm{~cd}=1 \& \mathrm{cad}=\mathrm{rja} \&$ uact $=8 \&$ ved $=0 \mathrm{CB} 8 \mathrm{QFjAA} \& u r l=\mathrm{http} \% 3 \mathrm{~A} \% 2 \mathrm{~F} \% 2 \mathrm{Fwww}$.na.undp.org $\% 2 \mathrm{Fcon}$ tent $\% 2$ Fdam\%2Fnamibia\%2Fdocs\%2FDemGov\%2Fundp_na_demgov_UNCAC\%2520Gap\%2520Analysis \%2520report.pdf\&ei=Z25iVM-BKY7esATa9YHwAQ\&usg=AFQjCNF-OGtyWy33D9TNSla1pFczkHY6Dw [Accessed 5 August 2014].

Namibia Institute for Democracy in co-operation with the Konrad-Adenauer-Stiftung. 2000. Ethics and good governance in Namibia. http://www.google.com.na/url?sa=t\&rct=j\&q=\&esrc=s\&source=web\&cd=1\&c $\mathrm{ad}=$ rja\&uact $=8 \&$ ved $=0 \mathrm{CBwQFjAA} \&$ url $=$ http $\% 3 \mathrm{~A} \% 2 \mathrm{~F} \% 2 \mathrm{Fwww}$.nid.org.na\%2Fimages $\% 2 \mathrm{Fpdf} \% 2 \mathrm{Fgood}$ governance\%2FEthics_and_Good_Governance.pdf\&ei=jWosVY6rJ43Xaoa4gLAF\&usg=AFQjCNHYLkyD D68Fz3EYlbkGMDA26WSrSA\&sig2=Lr_UQQ8tX4ehXbA1LZPkhQ [Accessed 9 August 2014]. 
Namibian Stock Exchange (NSX). 2014. The corporate governance code for Namibia. Windhoek: Namibian Stock Exchange.

Nikodemus, S. 2013. Exploring the impact of work ethics on specific workplace practices in the ministry of Home Affairs \& Immigration. July. Windhoek: Polytechnic of Namibia.

Park, H. \& Blenkinsopp, J. 2013. The impact of ethics programmes and ethical culture on misconduct in public service organizations. International Journal of Public Sector Management, 26(7):520-533. https://doi. org/10.1108/IJPSM-01-2012-0004

Plant, K. 2008. Towards the development of a framework for ethics audits: An internal auditing perspective. Southern African Journal of Accountability and Auditing Research, 8:15-26.

Public Service of the Republic of Namibia. 2003. Being a public servant in Namibia. The pocket guide. http:// 172.16.5.46/eservice/ [Accessed 5 September 2014].

Rogojanu, A. \& Badea, L. 2011. Business ethics and education - an intelligent solution or a sustainable development? Equilibrium, 6(4):21-37. https://doi.org/10.12775/EQUIL2011.026

Rossouw, G. \& Van Vuuren, L. 2010. Business Ethics. 4th edition. Durban: Oxford University Press.

Schwartz, M.S. 2013. Developing and sustaining an ethical corporate culture: the core elements. Business Horizons, 56(1):39-50. https://doi.org/10.1016/j.bushor.2012.09.002

Sinclair, A. 1993. Approaches to organisational culture and ethics. Journal of Business Ethics, 12(1):63-70. https://doi.org/10.1007/BF01845788

Tabuena, J. 2009. Auditing governance effectively and usefully. Compliance Week, 6(69):48-49.

Talbot, J., Perrin, D. \& Meakin, D. 2014. Risk management and cultural virtue in HE co-delivery arrangements, Quality Assurance in Education, 22(2):109-124. https://doi.org/10.1108/QAE-12-2012-0047

Tjirera, E., Haimbodi, M. \& Hopwood, G. 2012. Risking corruption: Regional and local governance in Namibia. 9th Paper in the Anti-Corruption Research Series. http://www.ippr.org.na/sites/default/files/IPPR_\%20 RISKCORRUPTION_Paper9.pdf [Accessed 30 May 2015].

Treviño, L.K., Weaver, G.R. \& Brown, M.E. 2008. It's lovely at the top: Hierarchical levels, identities, and perceptions of organizational ethics. Business Ethics Quarterly, 18(2):233-252. https://doi.org/10.5840/ beq200818217

Valentine, S. \& Barnett, T. 2002. Ethics codes and sales professionals' perceptions of their organizations' ethical values. Journal of Business Ethics, 40(3):191-200. https://doi.org/10.1023/A:1020574217618

Vitell, S.J. \& Encarnación, R.H. 2006. The impact of corporate ethical values and enforcement of ethical codes on the perceived importance of ethics in business: A comparison of U.S. and Spanish managers. Journal of Business Ethics, 64(1):31-40. https://doi.org/10.1007/s10551-005-4664-5 